\title{
Contrast-Induced Nephropathy due to Coronary Intervention in a Diabetic Patient: A Case Report
}

\author{
İbrahim Caltekin*, Emre Gökçen, Atakan Savrun, \\ Şeyda Tuba Savrun, Bilgehan Demir and Erdal \\ Demirtaş \\ Department of Emergency Medicine, Malatya Research \\ and Training Hospital, Turkey \\ *Corresponding author: İbrahim Caltekin, \\ Department of Emergency Medicine, Malatya Research \\ and Training Hospital, Turkey
}

Received: J une 17, 2017; Accepted: July 03, 2017;

Published: July 21, 2017

\begin{abstract}
Contrast-induced nephropathy $(\mathrm{CIN})$ is a possible complication of coronary diagnostic and interventional procedures. Here, we present a diabetic patient admitted to our emergency department and diagnosed with CIN after repeated coronary interventions for myocardial infarction. It should be remembered that the incidence of CIN is higher in patients with concomitant diseases such as hypertension and diabetes mellitus.
\end{abstract}

Keywords: Contrast-inducednephropathy; Coronary intervention; Diabetes mellitus; Hemodialysis

\section{Abbreviations}

CIN: Contrast-Induced Nephropathy; PCI: Percutaneous Coronary Intervention; SCr: Serum Creatinine; HT: Hypertension; DM: Diabetes Mellitus; HD: Hemodialysis; LAD: Left Anterior Descending; RCA: Right Coronary Artery

\section{Introduction}

Contrast-induced nephropathy (CIN) is an acute decrease in renal function after the administration of an iodinated contrast agent in the absence of any other cause and defined with a transient increase in serum creatinine (SCr) levels in accordance with the baseline levels [1]. At the same time, CIN is a possible complication of coronary diagnostic and interventional procedures [2].

\section{Case Presentation}

70-year-old woman was admitted to emergency department with nausea, vomiting and oral intake impairment complaints. Hypertension (HT), diabetes and recently diagnosed coronary artery disease were present in her past medical history. Blood pressure was $140 / 90 \mathrm{mmHg}$, pulse rate was 92 beats/min, oxygen saturation was $92 \%$, respiration rate was 18 breaths/min and body temperature was $36.7^{\circ} \mathrm{C}$ in vital signs. Creatinine $9.31 \mathrm{mg} / \mathrm{dL}$, urea $158 \mathrm{mg} / \mathrm{dL}$, glucose $180 \mathrm{mg} / \mathrm{dL}$, and $\mathrm{K} 4.33 \mathrm{mmol} / \mathrm{L}$ were detected in laboratory findings. The patient was diagnosed with acute ST elevated anterior myocardial infarction one week earlier and the percutaneous coronary intervention (PCI) procedure was performed. It was seen that multiple artery occlusion (Figure 1) was detected and stent implantation was performed to the left anterior descending (LAD) artery and right coronary artery (RCA). It was found out that the coronary intervention procedure was repeated due to the chest pain of the patient and electrocardiography change at the following in coronary intensive care unit, and the procedure ended successfully after the coronary arteries were found to be clear (Figure 2).When the patient's laboratory values were examined one week earlier, it was determined that the urea and creatinine levels were in the normal range. The patient was diagnosed with CIN due to recurrent coronary intervention procedures and was transferred to the nephrology department for hemodialysis and treatment.

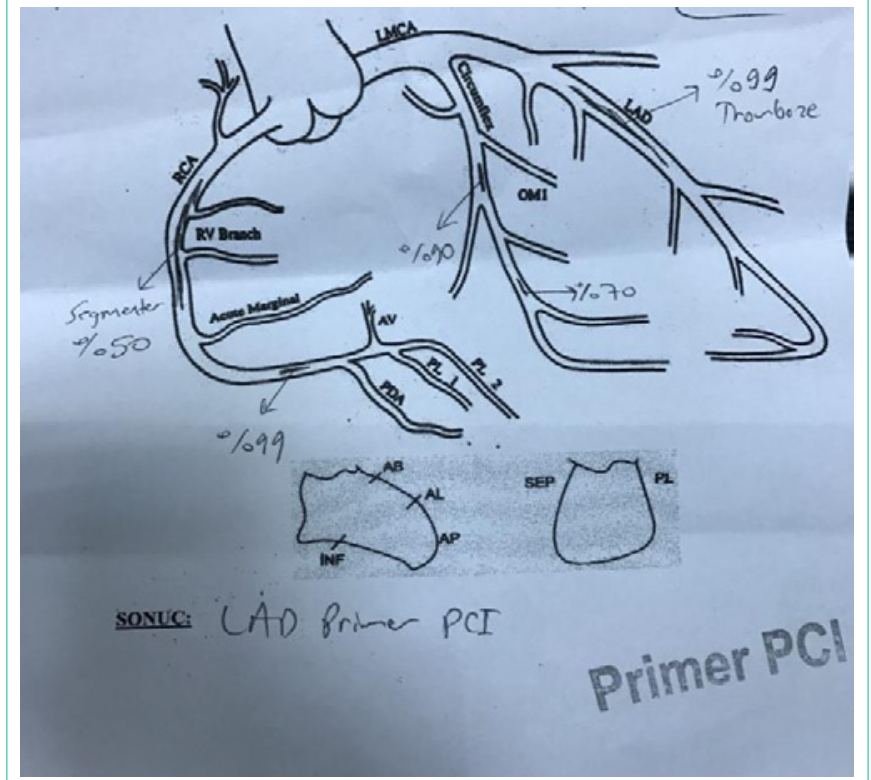

Figure 1: Multiple artery occlusion in coronary intervention.

\section{Discussion}

Between 1979 and 2002, the number of percutaneous cardiac interventions in the USA increased by $390 \%$. As the number of susceptible patients exposed to parenteral iodinated contrast media increases, contrast-induced nephropathy represents an increasing clinical problem [3].

Age, presence of diabetes mellitus, hypertension, degree of baseline renal insufficiency, volume of contrast material administered, congestive heart failure are well-known risk factors for CIN [4]. In the present case; age, diabetes mellitus, hypertension, volume of contrast material administered due to repeated coronary interventions were facilitating factors for CIN.

In conclusion, CIN causes in-hospital morbidity, increased mortality, prolonged hospitalization, increased health care costs, and potentially irreversible decline in renal function. It should be kept
Austin J Nephrol Hypertens - Volume 4 Issue 1 - 2017 ISSN : 2381-8964 | www.austinpublishing group.com Caltekin. (C) All rights are reserved
Citation: Caltekin I, Gökçen E, Savrun A, Savrun ŞT, Bilgehan Demir and Erdal Demirtaş. Contrast-Induced Nephropathy due to Coronary Intervention in a Diabetic Patient: A Case Report. Austin J Nephrol Hypertens. 2017; 4(1): 1067 




Figure 2: Clearcoronary arteries in second coronary intervention.

in mind that high-dose contrast media which can be used in certain procedures such as coronary intervention may cause CIN, and the incidence of CIN is higher in patients with concomitant diseases such as HT and DM.

\section{References}

1. Solomon R. The role of osmolality in the incidence of contrast-induced nephropathy: a systematic review of angiographic contrast media in high risk patients. Kidney Int. 2005; 68: 2256-63.

2. Marenzi G, Lauri G, Assanelli E, Campodonico J, De Metrio M, Marana I, et al. Contrast-induced nephropathy in patients undergoing primary angioplasty for acute myocardial infarction. J Am CollCardiol. 2004; 44:1780-5.

3. Efstratiadis G, Pateinakis P, Tambakoudis G, Pantzaki A, Economidou D, Memmos D. Contrast media-induced nephropathy: case report and review of the literature focusing on pathogenesis. Hippokratia. 2008; 12: 87-93.

4. Solomon RJ, Mehran R, Natarajan MK, Doucet S, Katholi RE, Staniloae CS, et al. Contrast-induced nephropathy and long-term adverse events: cause and effect? Clin J Am SocNephrol. 2009; 4: 1162-9.
Austin J Nephrol Hypertens - Volume 4 Issue 1 - 2017

ISSN : 2381-8964 | www.austinpublishinggroup.com

Caltekin. (C) All rights are reserved
Citation: Caltekin I, Gökçen E, Savrun A, Savrun ŞT, Bilgehan Demir and Erdal Demirtaş. Contrast-Induced Nephropathy due to Coronary Intervention in a Diabetic Patient: A Case Report. Austin J Nephrol Hypertens. 2017; 4(1): 1067 